Forthcoming in Pacific Philosophical Quarterly. DOI 10.1111/papq.12364

Please cite the published version.

\title{
Lucky Ignorance, Modality and Lack of Knowledge
}

\author{
Oscar A. Piedrahita
}

\begin{abstract}
I argue against the Standard View of ignorance, according to which ignorance is defined as equivalent to lack of knowledge, that cases of environmental epistemic luck, though entailing lack of knowledge, do not necessarily entail ignorance. In support of my argument, I contend that in cases of environmental luck an agent retains what I call epistemic access to the relevant fact by successfully exercising her epistemic agency and that ignorance and non-ignorance, contrary to what the Standard View predicts, are not modal in the sense that knowledge is. After responding to objections, I conclude by sketching an alternative account of ignorance centered on the notions of epistemic access and epistemic agency.
\end{abstract}

\section{Introduction: Ignorance as Lack of Knowledge}

There are definitional and axiological aspects of ignorance. Definitional are the aspects that explain what ignorance is, its nature. To offer a definitional account of ignorance is to say, for instance, what makes the sentence 'S is ignorant that $p$ ' true, independently of the content of $p$ and of who $\mathrm{S}$ is. Axiological are the aspects of ignorance that contingently accompany the definitional aspects and that typically are the subject matter of social epistemology: what $p$ 's content is, how S came to believe it, what S's identity is, and how she maintains her belief.

This paper is about the definitional aspects of ignorance, which are normally taken to be independent of the axiological ones. The mainstream approach in analytic epistemology of ignorance has it that an account of what makes 'S is ignorant that $p$ ' true need not capture all the connotations of the expressions 'ignorance' or 'to be ignorant'. For instance, it is intuitively true that ignorance and its 
cognates refer to some kind of epistemic deficiency or can be used in an epistemically derogative way (as in 'flat-Earthers are ignorant'). Even though this and similar aspects of ignorance are important, analytic epistemologists don't think that they determine what ignorance is. ${ }^{i}$

In the definitional debate about ignorance, the standard account holds that being ignorant that $p$ is equivalent to not knowing that $p$. That is, lack of knowledge is a necessary and sufficient condition for ignorance..$^{\text {ii }}$

Standard View of ignorance (SV): S is ignorant that $p$ if and only if S lacks knowledge that $p$.

The SV entails that ignorance and knowledge are contradictories: non-ignorance if and only if knowledge, and non-knowledge if and only if ignorance. A defender of SV, Pierre Le Morvan, puts it this way: under SV, ignorance and knowledge are 'mutually exclusive and exhaustive' (2011b, 335). Relatedly, and importantly, SV maintains that ignorance has no substantive or positive nature (cf. Le Morvan and Peels 2016, 17 and ff.). Although 'knowledge' is part of the analysans, SV doesn't presuppose any account of knowledge nor any substantive epistemological claim. SV is taken to be an account of the nature of ignorance, not of the nature of knowledge: what the former is has no bearing on what the latter is, and vice versa. Although in this paper I aim to show that this is misguided, the proponent of SV believes that her view is not proved true or false by any substantive claim about knowledge.

SV is orthodoxy in epistemology, and for good reason: it's not only well-supported by linguistic intuitions (cf. Le Morvan and Peels 2016, 15-16), but it's also philosophically plausible. ${ }^{\text {iii }}$ To begin, parsimony seems to recommend SV. That is, if ignorance is an absence of knowledge, a theory of either of these —i.e. ignorance and knowledge — may ipso facto provide an explanation of the other. Also, SV promises us a unified account of ignorance and knowledge: in all cases in which we find one to be ignorant, we find one lacking knowledge.

There's a second orthodoxy of epistemological theorizing: knowledge excludes epistemic luck.iv Beliefs that are true due to veritic epistemic luck (such as lucky guesses, wishful thinking, as well as 
beliefs formed in barn-façade and Gettier-type cases) don't count as knowledge. These two orthodoxies of contemporary epistemology entail that lucky true beliefs, and even justified lucky true beliefs, are instances of ignorance.

Accounts of ignorance aim to explain not only propositional or factive ignorance (that is, ignorance that or whether a proposition's truth conditions), but also procedural (or how-to ignorance) and objectual ignorance (or ignorance of something). In this paper, I focus on factive ignorance. ${ }^{v}$ Given that ignorance and knowledge are contradictories, there are at least four ways of being ignorant under SV:

As belief is necessary for knowledge, there's doxic ignorance when some proposition $p$ is true and $\mathrm{S}$ doesn't believe that $p$ (i.e., $\mathrm{S}$ either disbelieves or suspends belief in $p$, or otherwise has never occurred to her to believe that $p$ ).

As truth is necessary for knowledge, there's alethic ignorance when $p$ is true and $\mathrm{S}$ believes that not- $p$.

Assuming that justification is necessary for knowledge, there's justification ignorance when $\mathrm{S}$ truly but unjustifiably believes that $p$.

Assuming that there's an anti-luck necessary condition for knowledge, there's luck ignorance when S truly and justifiably believes that $p$, but her so believing doesn't meet an anti-luck condition (or whatever condition is needed to deal with Gettier and barn-façade cases).

SV is very compelling. ${ }^{\text {vi }}$ But, as I'll argue in this paper by focusing on luck ignorance, it might be wrong. Indeed, by considering certain cases of epistemic luck —environmental luck— we are naturally led to the conclusion that an agent might lack knowledge and yet not be deemed ignorant. Though this sounds initially counterintuitive, I believe that such cases reveal serious shortcomings in our standard account of ignorance.

Here's the plan. In section 2, I present Duncan Pritchard's distinction between intervening and environmental epistemic luck. The former occurs when an agent forms a belief that is true due to a coincidental intervention between her method of belief formation and the target fact. By contrast, in 
cases of environmental epistemic luck, the agent forms a true belief that is free from this kind of coincidental intervention, and yet it is an easy possibility that her belief is false, given the epistemic environment she is in. In section 3, I argue that ignorance and knowledge differ in their modal profiles and that, although both kinds of epistemic luck are incompatible with knowledge, environmentally lucky true belief is not an instance of ignorance because it might be compatible with having epistemic access to the relevant fact. In section 4, I anticipate three possible lines of response to defend SV from the argument I present - I argue that they are either dialectically wanting or otherwise false in light of the distinction between environmental and intervening epistemic luck. I conclude in section 5 by suggesting an account of ignorance that is consistent with the main argument of this paper.

Before I start, I should say that I don't cause trouble to SV by proposing an alternative account of ignorance, nor does my argument indirectly supports competing accounts of ignorance on offer in the literature, such as the so called New View of ignorance for which ignorance is equivalent to lack of true belief. vii Indeed, the falsity of SV doesn't entail the truth of any other account of ignorance. Given that SV credits itself of being uncontroversial, I challenge this by inspecting the matter under the light of relatively uncontroversial epistemological theses about luck, i.e., that veritic epistemic luck is incompatible with knowledge, that there's distinction between environmental and intervening epistemic luck.

\section{Veritic Epistemic Luck: Environmental and Intervening}

Most epistemologists take it as uncontroversial that epistemic luck prevents a true belief, and even a justified true belief, from constituting knowledge. viii At least since Gettier's classic paper (1963), epistemologists have been in the business of offering accounts of knowledge that avoid granting knowledge to agents whose beliefs are true as a matter of luck. The kind of luck that undermines knowledge has been called veritic epistemic luck (Engel 1992, Pritchard 2005, ch. 6). Many also agree that cases of veritic epistemic luck aren't all of the same kind, i.e., luck may undermine knowledge in 
different ways. ${ }^{\text {ix }}$

What's crucial to veritic epistemic luck is that an agent forms a belief that is true in a lucky way. One way this could happen is when S justifiably forms a belief that is true because, given an unbeknownst intervention, the target fact that makes the belief true ends up obtaining. Were there no lucky intervention, the agent would not form a true belief. This is the kind of luck exhibited in Gettiertype cases; following Pritchard, I shall call this intervening epistemic luck (henceforth intervening luck).x. A toy example of intervening luck involves a shepherd who sees in the distance a sheep-shaped dog (Chisholm, 1977). On the basis of her perception, she forms the belief that there is a sheep. But the sheep-shape she perceives isn't actually a sheep. However, the agent's circumstances are such that, unbeknownst to her, there is a sheep standing right behind the dog, so the belief ends up being true, yet luckily so.

According to a second kind of knowledge-undermining luck, S's justified true belief is lucky when her method of belief formation, relative to the environment she is in, could have easily led her to not form a true belief. Unlike the previous kind of epistemic luck, nothing intervenes between the belief, the conditions in which it is formed, and the target fact, since the agent forms the belief on the basis of evidence that is connected to the target fact that makes the belief true. The luck lies rather in the connection, which is lucky because of the unnoticed easy possibility of there not being a connection between the evidence and the target fact. Pritchard calls this environmental epistemic luck (henceforth, environmental luck). A toy example of environmental luck is the barn-façade case (cf. Goldman 1976): a tourist driving around barn-façade county sees what seems to be a barn and forms the belief that there is a barn. It turns out, however, that in barn-façade county most things that look like barns are (fake) barn-façades; however, she happens to see the only real barn in the county. So, her belief is true; but it's true by luck, given that it could have easily been the case that the tourist, being in front of a fake-barn, forms the belief that there is a barn.

Being species of veritic epistemic luck, both intervening and environmental luck are 
incompatible with knowledge. The reason is that in order to count as knowledge, a belief not only needs to be true, but also be formed in such a way that it would be true in relevantly different but related counterfactual circumstances. ${ }^{x i}$ Furthermore, we see the sense in which knowledge (or its necessary conditions) ${ }^{x i i}$ is modal: to assess whether $\mathrm{S}$ has knowledge, we not only assess what $\mathrm{S}$ believes and what obtains in the actual world, but also in nearby possible worlds. I shall come back to this issue in the next section, but it suffices to say at the moment that S's true beliefs count as knowledge when neither S's epistemic environment, nor S's method and evidence for forming beliefs, could have led her to easily form false beliefs. Now, both intervening and environmental luck illustrate the situation of agents who form beliefs that could have easily been false, either because the belief would be normally false, or the belief is formed in an epistemically unfriendly environment. ${ }^{\text {iii }}$

A key difference between intervening and environmental luck is the role played by what I call epistemic access to the target fact, which refers to the explanation of why an agent forms a true belief. When believing that $p, \mathrm{~S}$ has epistemic access to the fact that $p$ (henceforth, epistemic access to $p$ ) iff: Truth condition: $p$ is true; Epistemic agency condition: that $\mathrm{S}$ has the belief that $p$ is explained by $\mathrm{S}$ 's exercise of her epistemic agency (which includes her cognitive faculties, abilities, or capacities); and

Truth $\bigoplus$ epistemic agency condition: that $\mathrm{S}$ forms the true belief that $p$ is explained by $\mathrm{S}$ 's exercise of her epistemic agency.

How do these conditions relate to each other? If you have a false belief, or if you suspend judgement, you don't have epistemic access to the relevant fact. That's what Truth condition captures. But having a true belief isn't sufficient to have epistemic access to the target fact you believe. For, as I am understanding it, epistemic access refers also to the way in which one forms a true belief. The Epistemic agency condition says then that one has epistemic access to a fact only if one forms the target belief because, and insofar, one exercises one's epistemic agency, which here is understood broadly: one's perception, one's memory, one's capacity to receive knowledge through testimony, one's 
reasoning abilities, etc. This condition is meant to capture this idea: you cannot have epistemic access to $p$ if someone brainwashed you into believing that $p$ or if having a concussion makes you believe that $p$. But the first two conditions aren't sufficient to have epistemic access, because not only your belief has to be true and formed because you exercise your epistemic agency. The fact that you ended up forming a true belief should also be explained by the fact that you exercised your epistemic agency. It is here where the distinction between intervening and environmental luck is important.

Environmentally lucky true beliefs are compatible with having epistemic access because they meet the three conditions above. In the case of the tourist, it is true that there's a barn, she forms this belief by exercising her perceptual abilities, and the fact that she forms this true belief is explained by the fact that she did so. ${ }^{\text {xiv }}$ In contrast, intervening lucky true beliefs aren't compatible with epistemic access, since what explains the fact that the agent ends up holding a true belief is the lucky intervention (as opposed to the fact that she exercised her epistemic agency). It is true that the shepherd exercised her epistemic agency when forming her belief; in that respect the shepherd meets not only the Truth condition, but also the Epistemic agency condition. But having epistemic access to a fact also requires that one's epistemic agency explains why the beliefs one forms are true. That the shepherd looked at a sheep-shaped $\operatorname{dog}$ (and formed the relevant belief on that basis) doesn't explain the fact that she formed a true belief. The latter is explained by the fact that there happened to be a sheep nearby. This is why exercising one's epistemic agency in forming a true belief by way of a coincidental intervention is not sufficient to have epistemic access to a fact. Even though both environmentally lucky true beliefs and intervening lucky true beliefs fall short of knowledge, the former are compatible with having epistemic access to the facts.

This difference between environmental and intervening luck is crucial because in the next section I will argue that an agent doesn't count as ignorant that $p$ insofar as she retains epistemic access to $p$, even if she fails to know that $p$. This presupposes a distinction between epistemic access and knowledge, which might seem unmotivated. For, after all, why does the tourist have epistemic access to the target fact and yet lack knowledge? As I understand the notion, epistemic access to $p$ might be 
necessary, but certainly insufficient for knowledge that $p$; and a true belief that $p$ is necessary, but insufficient, for epistemic access to $p$. In this sense, the notion is similar to that of cognitive achievement which some epistemologists discuss in connection with knowledge.xv Like the cognitive achievement / knowledge distinction, the epistemic access / knowledge distinction is meant to capture this idea: there are different ways of lacking knowledge and in some of them the not-knowledgeable subjects, in virtue of their exercise of their epistemic agency, are better off than their epistemic counterparts who lack epistemic. In this way, the epistemic access / knowledge distinction is meant to accommodate two different intuitions: that environmental luck is incompatible with knowledge (we are not willing to grant knowledge to the tourist) and that not all agents who lack knowledge and exercise their epistemic agency are on an equal epistemic footing. Agents who form environmentally lucky true beliefs are better off than agents who form intervening lucky true beliefs, or who guess or wishfully form true beliefs, in that their exercise of their epistemic agency is explanatorily relevant to their forming true beliefs. Their environment might preclude them from knowing, even if there is no fault, epistemically speaking, on their part.

\section{Epistemic Luck, Ignorance, and Modality}

The distinction between intervening and environmental luck might seem irrelevant to a discussion of SV and the nature of ignorance. If both kinds of epistemic luck are incompatible with knowledge, and if ignorance is lack of knowledge, then both intervening and environmental luck yield ignorance. End of story.

Indeed, the idea that lucky true beliefs are not cases of ignorance isn't a new issue for SV.xvi Rik Peels, for instance, has already contended that our intuitions regarding our ascriptions of ignorance to agents who form true beliefs due to veritic epistemic luck are at odds with SV:

I enter my living room and look at the clock. The clock tells me that it is 3 p.m., so that I acquire the belief that it is 3 p.m. I know that the clock has always worked fine, but I have no idea that the clock 
stopped working 24 hours ago. Would we say that in this Gettier-type case I am ignorant that it is 3 p.m.? It seems implausible to say that I am. (Peels, 2011, 352)

Confronting cases such as this, the proponent of SV argues that denying the existence of luck ignorance is based on a misunderstanding:

While this [i.e. that Peels is ignorant that it is 3 p.m.] seems implausible to Peels, is it to the rest of us? In his imagined case, Peels has a belief that just happens to be true by sheer luck or accident and one based on the false belief that his clock is presently indicating the correct time. On the Standard View, Peels is ignorant in this case of the fact that it is 3 despite his having this true belief. Now, of course, in having the belief that it is 3 p.m., Peels is not ignorant of something. But what that something is can be explained on the Standard View as the proposition that it is 3 p.m. (else he could not presumably have the belief that it is 3 p.m.), and this is a different matter from his not being ignorant of the fact that it is 3 p.m. (where not being ignorant of this fact amounts to not being ignorant that the state of affairs of it being 3 p.m. obtains). (Le Morvan, 2012, 388)

Le Morvan argues that a confusion between ignorance of facts and ignorance of propositions gives raise to the intuition that there's no luck ignorance involved in the case. Roughly, when S's belief that it's 3 p.m. is luckily true, $\mathrm{S}$ is not ignorant of the proposition that is expressed by the sentence 'it's 3 p.m.', i.e., $\mathrm{S}$ is in a position to entertain and understand this proposition's truth conditions. However, even though S isn't ignorant of the proposition, $\mathrm{S}$ is still ignorant of the fact that the proposition expressed by the sentence 'it's 3 p.m.' is true, i.e., she is ignorant that the truth conditions of this proposition obtain. But ignorance of propositions doesn't determine the nature of factive ignorance, for what is in question is whether the agent fails to grasp that a proposition's truth conditions obtain. xvii Thus, Le Morvan insists, insofar as an agent who forms a lucky true belief doesn't know that the truth conditions of the proposition she believes obtain, she lacks knowledge and hence is ignorant.

Given the dialectic above, exploiting certain cases of epistemic luck to leverage against SV seems like a dead-end. Notice, however, that in the debate no attention was paid to the different ways in which luck undermines knowledge. If we distinguish between environmental and intervening luck, 
it's possible to push forward the debate about the definitional aspects of ignorance while going beyond a mere clash of intuitions, or so I shall argue.

Consider, first, that the defender of SV says that it's impossible for S to avoid being ignorant that a proposition's truth conditions obtain unless $\mathrm{S}$ knows that they obtain. But this claim seems to assume that all cases of epistemic luck are cases of intervening luck, that is, cases in which an agent has no epistemic access to the fact that makes her belief true. ${ }^{\text {viii }}$ Le Morvan's version of SV deals with cases of epistemic luck by saying that agents who form lucky true beliefs merely entertain a proposition and thus fail to grasp that the proposition's truth conditions obtain. Now, although I concede that this might happen in cases of intervening luck (the shepherd entertains a proposition whose truth conditions don't match what she's actually seeing, i.e., a dog,), it is not true of cases of environmental luck. The tourist not only entertains the proposition that there is a barn; she was, as the case is described, presented with the truth-maker of the target proposition. Given that she forms the belief that there is a barn because she's actually seeing a barn, she also grasps that the truth conditions of the target proposition obtain. Once we see that all epistemic lucky true beliefs are not created equal, and that some of them are compatible with having epistemic access to the facts, we have a prima facie reason to think that ignorance isn't lack of knowledge, since one can lack knowledge without thereby failing to grasp that one's believed proposition's truth conditions obtain.

Start by observing a difference between ignorance and knowledge. Knowledge is a modal notion. As suggested before, the idea behind the claim that luck is incompatible with knowledge is that the concept of knowledge is defined over entities in both the actual world and relevant possible worlds. One cannot determine whether a belief constitutes knowledge by simply examining the facts that obtain in actuality. Knowledge, that is, ranges over two different axes, i.e., over what an agent believes in the actual world and what she believes in nearby possible worlds. This is why a belief constitutes knowledge not only if it's true in the actual world, but also in nearby possible worlds in which the subject forms the belief given the same evidence and the same method of belief formation. 
I take it that SV is committed to the claim that ignorance and non-ignorance are modal notions. More particularly, SV treats ignorance and non-ignorance as modal notions when it comes to Gettier and barn-façade cases, in which a justified true belief isn't sufficient to avoid being ignorant. That's why SV predicts the existence of luck ignorance. Given that, under SV, ignorance and knowledge are contradictories (again: ignorance iff non-knowledge, and knowledge iff non-ignorance), it is committed to the following claim, which is just a corollary of SV:

Modality of ignorance: for any given proposition $p, \mathrm{~S}$ is ignorant that $p$ unless S's believing that $p$ meets the modal condition necessary for knowledge.

According to Modality of ignorance, one's state of ignorance can be determined by modal facts, in that even if one's belief that $p$ is true in actuality, one still count as ignorant that $p$ 's truth conditions obtain provided that the belief is false in relevant and nearby possible worlds. Its commitment to Modality of ignorance leads SV to say that both the tourist and the shepherd are ignorant that there is a barn and that there is a sheep, respectively; their beliefs, even if true, don't meet the modal condition necessary for knowledge.

However, there are grounds to believe that Modality of ignorance is false and that ignorance and non-ignorance aren't modal in the same way that knowledge is. Ignorance is the kind of concept that is evaluated along one axis; it ranges over the (lack of) beliefs and what obtains in the actual world. Remember that, in the epistemological debate, a necessary condition of factive ignorance is that it's a doxastic attitude (or a lack thereof) that fails to represent what is the case, where such a failure consists in failing to grasp that a proposition's truth conditions obtain or are satisfied. Now, if in order to determine whether an agent's doxastic state exhibits such a failure it's sufficient to assess their beliefs and the facts that obtain in the actual world, it follows that ignorance is non-modal. In order to determine whether an agent is ignorant or non-ignorant that $p$, it's irrelevant whether her belief that $p$ meets or fails to meet the modal condition necessary for knowledge. That is, to determine whether $\mathrm{S}$ is ignorant that $p$ we don't need to evaluate whether: 
(a) $\mathrm{S}$ believes that $p$ across a relevant set of possible worlds; or

(b) S falsely believes that $p$ across a relevant set of possible worlds.

On the contrary, ascriptions of ignorance are warranted by assessing the agent's beliefs and the facts that obtain in the actual world. Given that ignorance is understood as factive ignorance, in order to determine whether an agent's doxastic attitude fails to represent what is the case (i.e., fails to grasp a proposition's truth conditions), it suffices with evaluating the agent's beliefs and what obtains in the actual world.

To see an example, suppose that the tourist is now in all-real-barns-but-one county. This county is populated with many real barns and there's only one fake barn. Again, the tourist doesn't know this particularity of her environment and happens to see a barn-façade at a distant field. The tourist forms the belief that there is a barn in the field but, unluckily, she's looking at the only fake barn in the county. However, in most nearby possible worlds in which she looks at what seems to be a barn and forms the corresponding belief, her belief is true. Now, intuitively, given that the tourist's belief is false, she's alethic ignorant that there's a barn. And we rightly ascribe ignorance to the tourist without taking into consideration that there are many close possible worlds in which she's looking at a real barn and her belief is true. We can say that the tourist isn't ignorant in those close possible worlds in which she forms a true belief that there is a barn, which then entails that in order to ascribe ignorance to an agent in the actual world we don't necessarily take into consideration whether she is also ignorant in nearby possible worlds. Thus, ignorance, unlike knowledge, is a function of what an agent believes and what obtains in the actual world.

Ignorance thus is non-modal because in order to fail to believe what is the case in the actual world, it's not necessary that the agent's doxastic state exhibits a failure to believe what is the case in counterfactual scenarios. The proponent of SV might respond that the previous case only shows that alethic ignorance is non-modal, which is obvious because there is nothing modal in not having a true belief. What the proponent of SV is committed to is that Modality of ignorance is true because, and 
insofar as, to determine whether agents are not luck ignorant is necessary to take into consideration counterfactual scenarios. The argument against SV is thus incomplete, and I need to show that ignorance is non-modal in the additional sense that there are cases in which in order to be nonignorant, it's not necessary that the agent's doxastic state meets the modal condition necessary for knowledge. In particular, I need to show a case in which:

(i) $\mathrm{S}$ forms a belief whose truth lacks modal robustness, i.e., it falls short of knowledge; and

(ii) S forms a belief that doesn't fail to represent what is the case in the actual world (in the sense that $\mathrm{S}$ grasps that the truth conditions of the proposition obtain), i.e., it's an instance of non-ignorance.

Environmental lucky true beliefs can meet these two conditions. In such cases, an agent's true belief fails to meet the modal condition necessary for knowledge, and yet this doesn't prevent the agent from grasping that the truth conditions of the proposition she believes obtain. The agent doesn't fail to grasp that the target proposition's truth conditions obtain because she has epistemic access to the target fact. For according to the account of epistemic access sketched above, the belief that $p$ constitutes epistemic access because the fact that one successfully exercises one's epistemic agency explains that one's belief represents the world as it actually is. This is, in any case, true of the tourist: that she forms a true belief that there is a barn is explained by the fact that she exercised her perceptual abilities when being in front of the barn. One is not merely entertaining the proposition that there is barn when one believes that there is a barn after being in front of the truth-maker. That is, an agent who forms an environmentally lucky true belief, in virtue of having epistemic access to the target fact, may not fail to grasp that the proposition's truth conditions obtain in the actual world. Of course, in counterfactual scenarios the tourist's belief might fail to represent what is the case (because, say, in those possible worlds she believes that there is a barn when being in front of a fake-barn). But this is part of the modal robustness that precludes her belief from constituting knowledge, which differs from ignorance in their modal profiles. Whatever the epistemic status of the tourist's beliefs in those nearby possible worlds, it 
is still true that in actuality she has epistemic access to the target fact. Ignorance and non-ignorance are then non-modal in the particular sense that, contrary to what SV predicts, one can escape the state of ignorance without meeting the modal condition necessary for knowledge and one's failure to meet the modal condition necessary for knowledge is not sufficient to make one ignorant (provided that one, in virtue of having epistemic access to the target fact, doesn't fail to grasp that the target proposition's truth conditions obtain).

Now, it follows that environmental lucky true beliefs can fall short of knowledge without yielding ignorance, which in turn implies that lack of knowledge is not equivalent to ignorance. We have thus a clear case against SV: ignorance is not equivalent to lack of knowledge because one can lack knowledge and at the same time lack ignorance. How so? By forming a belief that, despite falling short of knowledge, grants one epistemic access to the targe fact.

Compare with intervening lucky true beliefs and notice that they don't meet condition (ii) above. The shepherd who confuses a sheep-shaped dog with a sheep fails to grasp that the truth conditions of the proposition believed obtain given that she lacks epistemic access to this fact. On the one hand, the shepherd entertains a proposition whose truth conditions don't match what she's seeing in her actual circumstances — the proposition that is the content of the shepherd's belief is different from the fact she was presented with. On the other hand, and as mentioned before, even though the shepherd forms the belief by exercising her epistemic agency, that she forms that truth belief isn't explained by such exercise; her believing truly depends on the lucky intervention in the environment.

It's important to clarify that the argument presented doesn't rely on, nor entails, that every true belief isn't a case of ignorance. This would entail that the argument against SV gives indirect support to the New View of ignorance, which I also reject. The argument presented seeks to establish that only environmentally lucky true beliefs are compatible with non-ignorance, since they differ from other true beliefs that fall short of knowledge in that the agent's epistemic agency explains why the relevant belief exhibits no failure in representing what is the case in the actual world, even if it's false in nearby possible 
worlds. What is wanting in environmentally lucky true beliefs is that the agent's epistemic access to the target fact isn't sufficient for knowledge, given that her belief's being true is modally unstable.

Alternatively, the problem with environmentally lucky true beliefs is the kind of epistemic environment in which they are formed, and not the way in which they are formed. The situation is different with other lucky true beliefs, such as lucky guesses, wishful thinking or intervening lucky true beliefs. They, according to the argument developed here, might still be cases of ignorance, since even if true, they fail to grant the subject epistemic access to the target fact.

There's another possible source of misunderstanding that I should set to one side. I've said that in cases of environmental luck one can lack both knowledge and ignorance that $p$ and at the same time have epistemic access to $p$, where this access falls short of knowledge given the lack of modal robustness. A critic can say that this is misguided, given that the notion of epistemic access is itself modal. Specifically, the target notion states that a subject has epistemic access in her belief that $p$ only if her believing truly is explained by her exercise of her cognitive abilities. And explanation and exercising an ability can be construed modally. The criticism would be then that I have misleadingly replaced one modal notion (knowledge) by another (epistemic access). However, even if explanation and abilities can be construed modally, I don't think that makes ignorance or non-ignorance modal notions in the sense that SV does. Whether someone has epistemic access to $p$ in actuality is a fact about the relationship between an agent and the world, given the way she forms her belief. This doesn't require that her belief should be true in other possible worlds, even if the agent's possession of her epistemic agency in actuality depends on her exercising it in counterfactual scenarios. ${ }^{\text {xix }}$

Summing up, ignorance isn't equivalent to lack of knowledge because one's belief that $p$ can be an instance of both non-knowledge and non-ignorance. Ignorance and knowledge, differing in their modal profiles, track two different aspects of our epistemic environment: whereas ignorance depends on what the agent believes and obtains in actuality, knowledge depends on the epistemic quality of the agent's beliefs in counterfactual scenarios. But, as long as in cases of environmental luck the agent has epistemic access to the target fact in the actual world, we can say that she isn't ignorant in the actual 
world, even if she lacks knowledge both in the actual world and in nearby worlds.

\section{How may proponents of the Standard View resist this argument?}

I shall now propose and address three possible lines of response to the argument presented in the last section. Rather than being objections proper, these possible responses are features of SV that could possibly save it from the previous argument. One thing I hope to make clear is that each line of response comes with a price, i.e., making SV no longer a plausible account of ignorance, which is precisely part of its appeal.

\subsection{Ignorance has no nature hence the Standard View is irrefutable}

The first possible response is related to what SV is taken to entail. Under SV, ignorance is defined as lack of knowledge, irrespective of what knowledge is, since ignorance has no substantive or positive nature (Le Morvan and Peels 2016, 17). As already mentioned in the introduction, SV doesn't presuppose any account of knowledge nor any substantive epistemological claim. It's an account of the nature of ignorance, not of the nature of knowledge: what the former is has no bearing on what the latter is, and vice versa. Since under SV ignorance is the lack of whatever any account of knowledge takes knowledge to be, different accounts of knowledge will give different results about particular cases of ignorance. For instance, SV predicts that if there is lucky knowledge (cf. Hetherington 2001), then there's no luck ignorance for that account of knowledge.xx The key point, and the one I'm addressing here, is that SV takes itself to be true independently of any substantial epistemological claim and thus it's not proved true or false by a theory of knowledge (cf. Le Morvan and Peels 2016, 18 and ff.). Therefore, even if in cases of environmental luck S has epistemic access to the target fact, she is still ignorant, for the sole reason that ignorance is whatever an epistemological theory considers as a lack of knowledge.

This line of response might seem appealing, but at this point of the dialectic is irrelevant. The idea that ignorance has no positive nature isn't convincing to someone who thinks, following what has 
been argued in the last section, that epistemic luck undermines knowledge in at least two different ways, and that one of them is compatible with there being access to the facts, which in turn doesn't entail ignorance. That ignorance has no positive nature just is the way ignorance is conceived under SV. In other words, the possible line of response presupposes the truth of SV and makes explicit what it entails. However, if the validity and correctness of SV is at issue, the claim that ignorance cannot be refuted by an epistemological argument cannot be compelling to someone who denies that ignorance is just the complement of knowledge. Thus, we need a further reason to take seriously the idea that ignorance has no positive nature, and that reason must be independent of the assumption that SV is true.

\subsection{Lucky true beliefs lack access to the facts hence they are cases of ignorance}

The second possible response to save SV consists in making a substantive claim about the nature of ignorance to the effect that, given other relevant epistemological concepts, the best theory of ignorance is SV even in cases of environmental luck. In a different context, Le Morvan (2011a) has offered such a claim. When discussing cases of accidental and lucky true belief, he says:

[In cases of epistemic luck], we have [...] situations where (i) $p$ is true, (ii) S believes that $p$, and yet (iii) S is ignorant that $p$. Why is S still ignorant that $p$ despite S's true belief that $p$ ? Because S's true belief that $p$ is merely accidentally true or true as a result of mere luck (2011a, 36).

This passage is followed by a clarification: in cases of epistemic luck, 'S did not know that $p$ because $\mathrm{S}$ has no cognitive access to the state of affairs in virtue of which S's belief that $p$ is true' $(2011 \mathrm{a}, 36$, fn. 9$)$. Given that ignorance is equivalent to not knowing, all cases of epistemic luck are instances of ignorance because $\mathrm{S}$ has no epistemic access to the facts that make her belief true.

Can Le Morvan's quoted words be used to save SV? Notice that they can be interpreted in at least two different ways. One possible reading is that $\mathrm{S}$ has no epistemic access to the facts in the sense that she doesn't have reflective access to what could make her true belief knowledge. That's to say, S has 
a true belief but remains ignorant because she is unaware that her belief could have easily been false. This is true of both intervening and environmental luck: the agents are unaware of why their respective beliefs are true. On this reading, ignorance is lack of knowledge because even in cases of lucky true belief, S has no reflective access to the relevant facts that would turn her belief into knowledge. However, this claim is too strong. For one thing, it's remarkably internalistic: only true beliefs formed in accordance with internalistic conditions would turn out to be knowledge -the rest would be plain ignorance. This is not only too demanding for most epistemic agents, but also favors epistemic internalism over epistemic externalism. It precludes SV from being a plausible and intuitive account of ignorance (at least for externalistic minded epistemologists). ${ }^{\mathrm{xxi}}$

A second, less strong reading of Le Morvan might be that even if S's belief is true, she is ignorant because she has no epistemic access to the relevant facts that are the content of her true belief. But this is only the case when S has a belief that is true due to intervening luck. Thus, Le Morvan's claim in favor of the SV, in the less strong reading, is false: not all cases of lack of knowledge, such as environmental luck, entail lack of epistemic access to the target fact. Thus, if ignorance isn't entailed by environmental luck when the agent, though lacking knowledge, has epistemic access, then it isn't equivalent to lack of knowledge.

\subsection{Ignorance is a modal notion too}

A different kind of response on behalf of SV could be that someone who has an environmentally lucky true belief is not ignorant.xxii If so, my argument has no force, because SV would now posit that (A) ignorance is equivalent to lack of knowledge and (B) environmentally lucky true beliefs can be instances of non-ignorance. However, I suspect that a defender of SV shouldn't appeal to this line of reply. For (A) and (B) entail:

(C) Environmentally lucky true beliefs can be instances of knowledge.

If environmentally lucky true beliefs are (or can be) instances of non-ignorance, they are instances 
of knowledge, because the latter is the contradictory of ignorance (under the Standard View). The problems now are, on the one hand, that (C) doesn't follow from SV. The adherent to SV cannot just commit to $(\mathrm{C})$ and save the day because SV is a view about the nature of ignorance and seeks to remain neutral about the nature of knowledge. $(\mathrm{C})$ is, nonetheless, a claim about the nature of knowledge. Thus, a defense of $(\mathrm{C})$ lies outside the resources available to an adherent to SV. On the other hand, most epistemologists think that $(\mathrm{C})$ is false. So, defending SV by committing to (C) seems like a desperate solution. It's ad hoc and unmotivated. It compromises the idea that SV should be uncontroversial.

A further, related line of reply on behalf of SV is to defend that ignorance is modal by retelling the barn-façade story. Suppose that $\mathrm{S}$ drives around barn-façade county, sees a barn, and forms the belief that there is a barn. Even if S has epistemic access to the target fact in the actual world, the environmental luck that affects her belief entails that she would lack epistemic access in nearby possible worlds. Now, if S lacks epistemic access in nearby possible worlds, we might still think that she is ignorant, since what distinguishes her belief in the actual world from her belief in nearby possible worlds is the environmental luck involved. Alternatively: one's true belief can amount to ignorance in virtue of the epistemic environment in which the belief is formed, provided that the environment makes salient the easy possibility of not having epistemic access to the target fact. So, environmentally lucky true beliefs are instances of ignorance, for the same reason that environmental luck precludes someone from having knowledge.

I think that this is a reasonable way of defending SV. There's a price though: to abandon the idea that ignorance has no positive nature and that a theory of ignorance doesn't make substantial epistemological claims. For to say that S's ignorance might depend on the epistemic quality of her beliefs given what obtains in other possible worlds is to add a modal component to the concept of ignorance. This is a substantive claim about the nature of ignorance, one that isn't directly derived from the claim 'ignorance is equivalent to lack of knowledge'. 
However, this line of argumentation not only comes with a price; it's also questionable. If ignorance is a lack of sorts, what does an agent or her doxastic state lack when she has a true belief that grants her epistemic access to the target fact? Remember that the reason she doesn't possess knowledge is that she is in an epistemically unfriendly environment. Her doxastic state doesn't lack anything that would have precluded it from being knowledge in a different (friendly) epistemic environment. This suggests that it's not entirely obvious that the concept of ignorance maps our doxastic attitudes and epistemic environment both in the actual world and in nearby possible worlds. To be sure, the concept of ignorance maps the former: we ascribe ignorance to those who form (true) beliefs out of biases, wishful thinking, guesses, lucky accidents. But does the concept of ignorance map the epistemic environment? If we judge that environmentally lucky true beliefs are instances of ignorance, it's because we are no longer taking into consideration the agent's exercise of her epistemic agency, but the epistemic environment she is in. One may certainly think that our concept of ignorance maps the epistemic environment, if one already embraces SV. For imagine an epistemic subject who exercises a huge deal of virtuous epistemic agency and always forms true beliefs due to the high quality of their epistemic agency. Assume that this agent is epistemically unfortunate: her beliefs are true, yet fall short of knowledge due to recalcitrant environmental luck. SV forces us to say that she is ignorant of all the truths she believes, even if her failing to acquire knowledge is not up to her but to external factors pertaining to her epistemic environment. But we shouldn't draw this conclusion, unless we are offered a reason to think that the concept of ignorance applies over and above the successful exercise of our epistemic agency when forming beliefs.

\section{Conclusion}

Let's take stock. I questioned the standard conception of ignorance as lack of knowledge by arguing that environmental luck, despite entailing non-knowledge, is compatible with having epistemic access to 
the target fact and hence with non-ignorance. I also argued that ignorance, unlike knowledge, isn't modal and this gives us reason to think that an agent who has epistemic access to a fact, even if lacking knowledge of that fact, isn't ignorant. The argument entails that ignorance and knowledge are not contradictories, as SV predicts, since one can lack both ignorance and knowledge (the argument thus entails that ignorance and knowledge can be contraries).

I haven't fully said what ignorance is, and yet the argument defended doesn't depend on an alternative account. The argument has only suggested that non-ignorance should entail having epistemic access to the relevant fact. This claim, for the moment, gives us at least a necessary condition for non-ignorance:

Factive non-ignorance: $\mathrm{S}$ is non-ignorant that $p$ only if $\mathrm{S}$ has epistemic access to fact that $p$.

Factive non-ignorance is neither an analysis, nor an account of, ignorance. Let me, however, conclude by suggesting how such an account might follow from the main argument of this paper.

The basic idea of such an account is that ignorance isn't defined by the lack of a particular doxastic state. Contrary to what SV and the New View of ignorance say, the nature of ignorance isn't exhausted by either lack of knowledge or lack of true belief. Roughly, since one can be non-ignorant and at the same time lack knowledge (in environmental luck scenarios), ignorance isn't equivalent to lack of knowledge. And since one can be ignorant while having a true belief (in intervening luck scenarios), ignorance isn't equivalent to lack of true belief. Thus, we have:

Denial of the SV: knowledge isn't necessary for non-ignorance.

Denial of the New View: true belief isn't sufficient for non-ignorance.

My suggestion is then that we can improve over SV and the New View by contending:

Right to left: Lack of epistemic access to $p$ is sufficient for ignorance that $p$, and

Left to right. epistemic access to $p$ is sufficient for non-ignorance that $p$.

These two claims give us this partial account of factive ignorance, which we can dub the 'Access View' 
of ignorance:

Access View of ignorance: For any true proposition $p, \mathrm{~S}$ is ignorant that $p$ if and only if $\mathrm{S}$ lacks epistemic access to $p$.

It's important to stress that this is a view of ignorance understood as a factive notion, that is, as ignorance of what is the case. xxiii Although this is not the place to attempt a defense of this view, two things are worth mentioning. On the one hand, the Access View is neither as permissive as the New View (which grants non-ignorance to anyone who has a true belief), nor as restrictive as SV (which deems ignorant those who, though lacking knowledge, have epistemic access to facts).

On the other hand, the Access View promises to be a powerful account of ignorance. Remember the components of having epistemic access to a fact: truth plus the way the belief is formed (epistemic agency) plus the explanation of why the agent forms a true belief. Thus, epistemic access to a fact isn't just a doxastic state. It is a very specific kind of epistemic state. According to the Access View, factive ignorance is better understood as a way of forming beliefs that prevents one from having epistemic access to the target fact. I take this as an interesting and potentially welcome result, since it in principle allows us to bring debates about the definitional and the axiological aspects of ignorance together. Social and feminist epistemologists think that ignorance isn't reducible to an absence of truth or knowledge, and understand ignorance as a complex set of practices and dispositional states influenced by the social, political and epistemic context. xxiv In the quarters of analytic epistemology, in contrast, discussions about the definitional aspects of ignorance focus on distinguishing different types of ignorance and finding the doxastic/epistemic state (or its lack thereof) that is common to all types of ignorance. These epistemologists neglect the social epistemology's approach, although they recognize that there might be complex social and political aspects that determine someone's lack of knowledge or true belief (cf. El Kassar 2018, and Peels 2019). Although the differences in their respective explanatory frameworks don't present the theorist of ignorance with a dilemma, it does pose the important question of what we can dispense with in an account of what, epistemologically, ignorance is. As the Access View 
entails that an account of ignorance shouldn't be oblivious to the way agents form their beliefs, it not only improves over SV, but is also relevant to discussions in social epistemology. Epistemic access to a fact, roughly understood as the quality and degree of one's epistemic agency when forming beliefs, can be sensitive to one's wider epistemic and social context. The optimal functioning of one's cognitive abilities, and the success of one's epistemic agency more generally, can depend on social and structural factors of one's environment. Corrupting epistemic and social practices (from lying and suppression of information to social segregation and polarization) not only might prevent us from getting at the truth. They might also determine who is trustworthy, what evidence is available for what beliefs, and what means are employed to relate the available evidence to our beliefs; that is, they might affect the quality of our epistemic agency. As long as the undermining of agents' epistemic agency can be useful to explain how ignorance is produced and maintained, the Access View nicely fits into the framework of social epistemology of ignorance. ${ }^{\mathrm{xx}}$

Oscar A. Piedrabita

Department of Philosophy

University of California, Irvine

i See El Kassar (2018) and Peels (2019) for discussion.

ii The SV can be found in Blome-Tillmann (2016), Bondy (2018), Dasgupta (2015), Driver (1989, 373-376), Fields (1994, 403), Haack (2001, 25), Lynch (2015), Turri et al. (2015), Unger (1975, 93), and Zimmerman (1988, 75; 2008, ix). In this chapter I focus on Le Morvan's defense of SV (2011a, 2011b, 2012, 2013, 2019).

iii See Le Morvan and Peels (2016) who present (without explicitly endorsing) various arguments in favour of SV (and also of the so-called New View of ignorance). Le Morvan, however, has individually defended SV.

iv See Engel for discussion (2015).

v See Le Morvan and Peels (2016, 15-16), and Nottelmann (2016), for a discussion of the different kinds of ignorance.

vi This doesn't mean that SV has no dissenters. See Kyle (2015, 2020), Peels (2010, 2011, 2012), Pritchard (Forthcoming).

vii See Peels $(2010,2011,2012)$. This view of ignorance can also be found in Goldman (1986, 26), Goldman and Olsson (2009, 19-21), Guerrero (2007, 62-63), van Woudenberg (2009, 375). I also think that the New View is problematic in light of the argument developed in this paper, although for space constraints I cannot argue this at length (although see the end of section 3 and the conclusion). 
viii A notable exception is Hetherington (2001).

ix Cf. Engel (2015), Hetherington (2011), Pritchard (2005, 2015), Turri (2013), Turri et al. (2015).

x See Pritchard (2012, 2015); Pritchard et al. (2010).

xi There are two salient ways of capturing the idea that justified lucky true beliefs are incompatible with knowledge. One may say that knowledge requires a belief that, besides true, is sensitive (cf. Dretske 1971, Nozick 1981), which means that if the target proposition were false, the agent wouldn't believe it. Alternatively, one may say that knowledge requires safe beliefs (cf. Sosa 1999, Williamson 2000, Pritchard 2005, 2012, 2015), which means that if the agent were to form a belief, it would not easily be false. My argument against SV doesn't rely on whether sensitivity or safety is the right anti-luck condition for knowledge.

xii I have in mind accounts of knowledge for which knowledge-conducive abilities are understood modally or entail safety (cf. Greco 2007, 2012, forthcoming; Sosa 2007; Turri 2011).

xiii I am setting aside those (controversial) accounts for which knowledge is compatible with veritic epistemic luck (cf. Hetherington 2001) or with environmental epistemic luck (cf. Lycan 2006; Sosa 2007, ch. 5; Turri 2012).

xiv The tourist certainly lacks epistemic access to related facts relevant to her epistemic environment, but this doesn't prevent her from having access to the target fact, i.e., that there's a barn.

xv Cf. Greco (2007, 2012); Pritchard (2012); Pritchard et al. (2010, ch.2); Sosa (2007, ch. 5). Whereas Greco and Sosa understand knowledge in terms of cognitive achievement, Pritchard thinks that they come apart in both directions. Although the notion of cognitive achievement is by no means univocal, it differs from epistemic access in the sense that the latter doesn't presuppose the former (like when you form a true belief on the basis of testimony). In this sense, one's having epistemic access to $p$ is less demanding than a cognitive achievement in one's true belief that $p$.

xvi Cf. Peels (2010, 2011, 2012), Pritchard (Forthcoming).

xvii For an elaboration of the distinction, see Le Morvan (2015) and for a discussion see Le Morvan (20011a, 2011b, 2012, 2013) and Peels (2010, 2011, 2012).

xviii I shall come back to this idea in section 4.2 when I address Le Morvan's contention that, in cases of epistemic lucky true beliefs, the agent fails to have knowledge because they have 'no cognitive access to the state of affairs in virtue of which' their beliefs are true (2011a, 36, fn.9).

xix A similar source of criticism can be that ignorance is modal because even believing is modal; at least if one has a dispositional account of believing: roughly, $\mathrm{S}$ believes that $p$ if $\mathrm{S}$ behaves as if $p$ is true in a given set of possible worlds. My answer is that even if a doxastic state like believing is modal, this doesn't entail that being ignorant is modal. For once, belief isn't a necessary condition for ignorance. More importantly, an alleged modality of believing has no bearing on the particular sense in which ignorance, unlike knowledge, isn't modal. In this particular sense, ascriptions of ignorance and belief don't depend on facts that obtain outside the agent in possible worlds, whereas ascriptions of knowledge do depend on facts that obtain outside the agent both in the actual and possible worlds. An alternative defense of the modality of ignorance, suggested by an anonymous referee for this journal, has it that some types of ignorance (i.e. doxic, alethic ignorance) are non-modal, whereas luck ignorance is modal. If luck ignorance is modal, then a rationale for that should be independent of the truth of SV (otherwise would be unconvincing). Furthermore, if SV entails that only luck ignorance is modal, the view would still be committed to Modality of ignorance which, as I am arguing, is false. In section 4.3 I further address the idea that ignorance is modal.

xx Cf. Le Morvan \& Peels (2016, 20-21) and Bondy (2018).

xxi An anonymous referee for this journal wonders whether Le Morvan can be taken to rather mean that both intervening and environmental lucky true beliefs entail ignorance because in both types of lucky true beliefs the subjects lack epistemic access to all the relevant facts. For instance, the tourist lacks epistemic access to the fact that 24 
she is looking at a real barn rather than to a fake barn, or to the fact that there are fake barns nearby. Although this suggestion would save SV, it would cause trouble somewhere else in our epistemology. For it entails that, for any proposition $p$, one is ignorant that $p$, unless one is non-ignorant of all the relevant facts that pertain to one's having knowledge that $p$. This claim is highly contentious and we should ask ourselves whether it's worth endorsing it just for the sake of saving SV. For the claim clearly raises too high the bar for having knowledge and would entail that we are ignorant of pretty much every true belief we have (which, again, is not something the defender of SV can easily make use of).

xxii I thank an anonymous referee for this journal for raising this issue.

xxiii Hence the caveat 'for any true proposition'. The Access View might infelicitously entail that one can be ignorant of falsehoods, since one cannot have access to the fact that corresponds to a false proposition. For someone who thinks that ignorance is only ignorance of facts, the caveat might seem redundant. For someone who thinks that ignorance is non-factive (cf. Le Morvan 2012,), the Access View's consequence that one can be ignorant of falsehoods might not seem problematic. For someone who thinks that this consequence is problematic, I recommend phrasing the Access View in a slightly but relevantly similar way: S is ignorant as to whether $p$ if and only if $\mathrm{S}$ lacks epistemic access to the fact that $p$. This would avoid the infelicity.

xxiv See the Introduction and essays in Sullivan and Tuana (2007), and essays in Gross and McGoey (2015). See also DeNicola (2017), El Kassar (2018), Harding (2006), Medina (2013), Tuana (2004, 2006).

xxv Versions of this paper were presented at the Universidad de Sevilla, UC Irvine, the Latam Freewill, Agency and Responsibility project, and the 2021 APA Eastern Division Meeting, where I received fruitful criticisms and suggestions. I want to thank Sven Bernecker, Louis Doulas, Annette Martin, David Mwakima, Sam Murray, Giulia Napolitano, Duncan Pritchard, Nick Smith, Alejandro Vesga, and two anonymous referees for Pacific Philosophical Quarterly for their written and generous feedback. This publication was made possible through the support of the grant \#61255 from the John Templeton Foundation. The opinions expressed in this publication are those of the author and do not necessarily reflect the views of the John Templeton Foundation

\section{References}

Blome-Tillmann, M. (2016). 'Ignorance and Epistemic Contextualism'. In The Epistemic Dimensions of Ignorance, Peels, R. and Blaauw, M. (eds.). Cambridge: Cambridge University Press, 96-113.

Bondy, P. (2018). 'Knowledge and Ignorance, Theoretical and Practical'. Social Epistemology Review and Reply Collective 7, 12, 9-14.

Chisholm, R. (1977). Theory of Knowledge (2nd ed.). Englewood Cliffs, NJ: Prentice-Hall.

Dasgupta, S. (2015). 'Inexpressible Ignorance’. Philosophical Review, 124 (4), 441-480.

DeNicola, D. (2017). Understanding Ignorance. The Surprising Impact of What We Don't Know. Cambridge, MA: The MIT Press. 
Dretske, F. (1971). 'Conclusive Reasons'. Australasian Journal of Philosophy, 49, 1, 1-22.

Driver, J. (1989). 'The Virtues of Ignorance'. The Journal of Philosophy 86 (7), 373-384.

El Kassar, N. (2018). 'What Ignorance Really Is: Examining the Foundations of Epistemology of Ignorance', Social Epistemology, DOI: 10.1080/02691728.2018.1518498.

Engel Jr. M. (1992). 'Is Epistemic Luck Compatible with Knowledge?’ Southern Journal of Philosophy 30: $59-75$.

Engel Jr. M. (2015). 'Epistemic Luck'. In Internet Encyclopedia of Philosophy, Fieser J., Dowden B. (eds.). URL = http://www.iep.utm.edu/epi-luck/.

Fields, L. (1994). 'Moral Beliefs and Blameworthiness'. Philosophy 69 (4), 397-415.

Gettier, E. (1963). 'Is Justified True Belief Knowledge?’ Analysis, 23, 121-123.

Goldman, A. (1976). 'Discrimination and perceptual knowledge'. Journal of Philosophy, 73, 771-791.

Goldman, A. (1986). Epistemology and Cognition. Cambridge, MA: Harvard University Press.

Goldman, A. and Olsson, E.J. (2009). 'Reliabilism and the Value of Knowledge'. In Epistemic Value. Haddock, A., Millar, A. \& Pritchard, D.H. (eds.). Oxford University Press, 19-41.

Greco, J. (2007). 'The Nature of Ability and Purpose of Knowledge', Philosophical Issues, 17, The Metaphysics of Epistemology (Special issue of Nous), 57-69.

Greco, J. (2012). 'A (Different) Virtue Epistemology'. Philosophy and Phenomenological Research, LXXXV (1), 1-26.

Greco, J. (2020). 'Knowledge-producing Abilities', in Virtue-theoretic Epistemology: New Methods and Approaches. C. Kelp and J. Greco (eds.). Cambridge: Cambridge University Press, 124-146.

Gross, M. and McGoey, L. (2015). Routledge International Handbook of Ignorance Studies (eds.). London: Routledge. 
Guerrero, A.A. (2007). 'Don’t Know, Don't Kill: Moral Ignorance, Culpability, and Caution'. Philosophical Studies, 136 (1), 59-97.

Haack, S. (2001). 'The Ethics of Belief Reconsidered. In Knowledge, Truth, and Duty: Essays on Epistemic Justification, Responsibility, and Virtue M. Steup (Ed.). Oxford: Oxford University Pres, 21-33.

Harding, S. (2006). ‘Two Influential Theories of Ignorance and Philosophy's Interests in Ignoring Them.' Hypatia, 21 (3), 20-36.

Hetherington, S. (2001). Good Knowledge, Bad Knowledge: On Two Dogmas of Epistemology. Oxford: Oxford University Press.

Hetherington, S. (2011). 'The Gettier Problem.' In The Routledge Companion to Epistemology. S. Bernecker and D. Pritchard (eds.). New York: Routledge.

Kyle, B. G. (2015). 'The new and old ignorance puzzles: How badly do we need closure?' Synthese, 192, $1495-1525$.

Kyle, B.G. (2020). ‘Truth and Ignorance.' Synthese https://doi.org/10.1007/s11229-020-02546-x

Le Morvan, P. (2011a). 'Knowledge, Ignorance, and True Belief.' Theoria 77 (1): 309-318.

Le Morvan, P (2011b). 'On Ignorance: A Reply to Peels.' Philosophia 39 (2): 335-344.

Le Morvan, P. (2012). 'On ignorance: A vindication of the Standard View.' Philosophia, 40(2), 379-393.

Le Morvan, P. (2013). 'Why the Standard View of Ignorance Prevails.' Philosophia, 41(1), 239-256.

Le Morvan, P. (2015). 'On the Ignorance, Knowledge, and Nature of Propositions.' Synthese, 192, 36473662.

Le Morvan, P. (2019). 'When Ignorance Excuses.’ Ratio; 32:22-31.

Le Morvan, P. and Peels, R. (2016). 'The Nature of Ignorance: Two Views.' In The Epistemic Dimensions of Ignorance, Peels, R. and Blaauw, M. (eds.). Cambridge: Cambridge University Press, 12-32.

Lycan, W. G. (2006). 'On the Gettier Problem problem.' In Epistemology futures S. Hetherington (Ed.). 
Oxford: Oxford University Press, 148-168.

Lynch, K. (2015). 'Willful ignorance and Self-deception.' Philosophical Studies, 173, 1-19. DOI 10.1007/s11098-015-0504-3.

Medina, J. (2013). The Epistemology of Resistance. Oxford: Oxford University Press.

Nottelmann, N. (2016). 'The Varieties of Ignorance.' In The Epistemic Dimensions of Ignorance, Peels, R. and Blaauw, M. (eds.). Cambridge: Cambridge University Press, 33-56.

Nozick, R. (1981). Philosophical Explanations. Oxford: Oxford University Press.

Peels, R. (2010). 'What Is Ignorance?’ Philosophia 38 (1): 57-67.

Peels, R. (2011). 'Ignorance Is Lack of 'True Belief: A Rejoinder to Le Morvan'. Pbilosophia 39 (2): $344-355$.

Peels, R (2012). `The New View on Ignorance Undefeated.' Philosophia 40 (4), 741-750.

Peels, R. (2019) 'Exploring the Boundaries of Ignorance: Its Nature and Accidental Features.' Social Epistemology Review and Reply Collective 8, no. 1, 10-18

Pritchard, D. (2005). Epistemic Luck. Oxford: Oxford University Press.

Pritchard, D. (2012). 'Anti-luck Virtue Epistemology.' The Journal of Philosophy, 19 (3), 247-279.

Pritchard, D. (2015). 'Anti-luck Epistemology and the Gettier problem.' Philosophical Studies, 172: 93 111.

Pritchard, D. (Forthcoming). 'Ignorance and Inquiry.' In American Philosophical Quarterly.

Pritchard, D., A. Millar, and A. Haddock (2010). The nature and value of knowledge: Three investigations. Oxford: Oxford University Press.

Sosa, E. (1999). 'How to defeat opposition to Moore.' Philosophical Perspectives, 13, 141-154.

Sosa, E. (2007). A virtue epistemology: Apt Belief and Reflective Knowledge (Vol. I). Oxford University Press. 
Sullivan, S. and Tuana, N. (2007). Race and epistemologies of ignorance (eds.). Albany: State University of New York Press.

Tuana, N. (2004). 'Coming to Understand: Orgasm and The Epistemology of Ignorance.' Hypatia, 19 (1), 194-232.

Tuana, N. (2006). 'The Speculum of Ignorance: The Women's Health Movement and Epistemologies of Ignorance.' Hypatia 21 (3): 1-19. doi:10.1111/j.1527-2001.2006.tb01110.x.

Turri, J. (2011). 'Manifest Failure: The Gettier Problem Solved.' Philosophers' Imprint: 11, No. 8, 1-11.

Turri J. (2012). 'Is Knowledge Justified True Belief?' Synthese 184: 247-59.

Turri, J. (2013). 'A conspicuous art: Putting Gettier to the Test.' Philosophers' Imprint, 13 (10): 1-16.

Turri, J., W. Buckwalter, and P. Blouw (2015). 'Knowledge and luck.' Psychonomic Bulletin \& Review, 22: $378-390$.

Unger, P. (1975). Ignorance: A Case for Skepticism. Oxford: Clarendon.

Van Woudenberg, R. (2009). 'Ignorance and Force: Two Excusing Conditions for False Beliefs.' American Philosophical Quarterly, 46 (4), 373-386.

Williamson, T. (2000). Knowledge and its Limits. New York: Oxford University Press.

Zimmerman, M.J. (1988). An Essay on Moral Responsibility. Totowa, NJ: Rowman and Littlefield.

Zimmerman, M.J. (2008). Living with Uncertainty: The Moral Significance of Ignorance. Cambridge University Press. 